\title{
Droplet activation, separation, and compositional analysis: laboratory studies and atmospheric measurements
}

\author{
N. Hiranuma ${ }^{1}$, M. Kohn ${ }^{2}$, M. S. Pekour ${ }^{1}$, D. A. Nelson ${ }^{1}$, J. E. Shilling ${ }^{1}$, and D. J. Cziczo ${ }^{1}$, \\ ${ }^{1}$ Atmospheric Sciences and Global Change Division, Pacific Northwest National Laboratory, 902 Battelle Blvd., Richland, \\ Washington, USA \\ ${ }^{2}$ Institute for Atmospheric and Environmental Sciences, Goethe-University Frankfurt am Main, Frankfurt, Germany \\ *now at: Earth, Atmospheric and Planetary Sciences, Massachusetts Institute of Technology, 77 Massachusetts Ave., \\ Cambridge, Massachusetts, USA
}

Received: 1 December 2010 - Published in Atmos. Meas. Tech. Discuss.: 24 January 2011

Revised: 29 June 2011 - Accepted: 6 October 2011 - Published: 26 October 2011

\begin{abstract}
Droplets produced in a cloud condensation nuclei chamber (CCNC) as a function of supersaturation have been separated from unactivated aerosol particles using counterflow virtual impaction. Residual material after droplets were evaporated was chemically analyzed with an Aerodyne Aerosol Mass Spectrometer (AMS) and the Particle Analysis by Laser Mass Spectrometry (PALMS) instrument. Experiments were initially conducted to verify activation conditions for monodisperse ammonium sulfate particles and to determine the resulting droplet size distribution as a function of supersaturation. Based on the observed droplet size, the counterflow virtual impactor cut-size was set to differentiate droplets from unactivated interstitial particles. Validation experiments were then performed to verify that only droplets with sufficient size passed through the counterflow virtual impactor for subsequent analysis. A two-component external mixture of monodisperse particles was also exposed to a supersaturation which would activate one of the types (hygroscopic salts) but not the other (polystyrene latex spheres or adipic acid). The mass spectrum observed after separation indicated only the former, validating separation of droplets from unactivated particles. Results from ambient measurements using this technique and AMS analysis were inconclusive, showing little chemical differentiation between ambient aerosol and activated droplet residuals, largely due to low signal levels. When employing as single particle mass spectrometer for compositional analysis, however, we observed enhancement of sulfate in droplet residuals.
\end{abstract}

Correspondence to: D. J. Cziczo

(djcziczo@mit.edu)

\section{Introduction}

Among the most uncertain processes in our current understanding of the climate system is the interaction of aerosol particles with water vapor to form clouds (IPCC, 2007). Changes in particle properties can affect clouds in several ways. For example, an increase in the number of particles in the presence of a constant amount of water vapor can result in more but consequently smaller droplets. Smaller and more numerous droplets resulting in more reflective clouds is known as the 1st indirect or Twomey effect (Twomey, 1974). Smaller droplets also initiate precipitation less effectively and this is called the 2nd indirect or Albrecht effect (Squires, 1958; Albrecht, 1989). More recently, Stevens and Feingold (2009) suggested that aerosol/cloud interactions are more complicated with both micro- and macrophysical buffers existing in the system. In all cases a more complete understanding of how particles form droplets is required to make headway in our understanding of climate.

The formation of droplets by particles when the vapor pressure of water is raised above saturation is theoretically well described. The vapor pressure of a solution droplet is enhanced by its curvature; this is known as the Kelvin effect (Thomson, 1871). Atmospherically occurring droplets are not pure water, however, and contain soluble material, which reduces the vapor pressure over the droplet according to Raoult's law (Raoult, 1887). The combination of these two effects leads to Köhler theory which predicts the critical supersaturation which must be overcome in order for a particle to activate as a droplet. This critical supersaturation is therefore a function both of the particle size and composition (Köhler, 1936). While Köhler theory is successful in predicting the supersaturation required to activate pure particles of some species (e.g. inorganic salts), atmospheric particles

Published by Copernicus Publications on behalf of the European Geosciences Union. 
are most often complex mixtures of components with a wide range of solubility (Murphy et al., 1998). For this reason, techniques to measure the abundance of cloud condensation nuclei $(\mathrm{CCN})$ have been developed. These so-called $\mathrm{CCN}$ chambers (CCNCs) pass aerosol particles through a region where they are exposed to a controllable supersaturation (Roberts and Nenes, 2005). Such chambers therefore do not explicitly rely on theory but instead measure the abundance of $\mathrm{CCN}$, often as a function of supersaturation, within an airmass. Alternatively, activation conditions for a given particle type can be determined as a function of size (Petters et al., 2009a; Moore et al., 2010).

One use of $\mathrm{CCN}$ abundance data is the formation of simple parameterizations of cloud drop number, which can be used at minimal computational expense in models (Lohmann and Feichter, 2005). Dusek et al. (2006) produced a simple parameterization by noting that in some cases size was a more important determinate of $\mathrm{CCN}$ formation than chemistry. Dusek et al. considered airmasses with predominantly aged continental aerosol particles and, despite the compositional similarity, at times size only captured $\sim 84 \%$ of the $\mathrm{CCN}$ variability. More recent research, especially that on more diverse particulate sources, has indicated chemistry does play a large role in CCN variability (Nenes et al., 2002; Petters and Kreidenweis, 2007; Rose et al., 2010). Nenes et al. (2002) showed in a model study that chemical effects can rival the 1st indirect effect in terms of radiative forcing. Petters and Kreidenweis (2007) suggested a single parameter, $\kappa$, to represent compositional effects on both hygroscopic growth below saturation and $\mathrm{CCN}$ activity. Values of $\kappa$ indicate a large difference between hygroscopic inorganic species (e.g. $\mathrm{NaCl}$ ) which largely follows Köhler theory $(0.5-1.4)$ and less active organics $(0.01-0.5)$. Petters and Kreidenweis (2007) determined $\kappa$ values for atmospheric particles in a range between 0.1 and 0.9. Rose et al. (2010) found somewhat lower values in the highly polluted conditions of Guangzhou, China, 0.1-0.5. The field study $\kappa$ average was observed to drop from 0.3 to 0.2 in the presence of significant organic-rich biomass burning.

Studies where the effect of composition on CCN formation was directly measured relied on particle generation from a known material in a laboratory setting (King et al., 2009; Shilling et al., 2007; Asa-Awuku et al., 2009). The problem with this strategy is that laboratory-generated particles do not undergo the complex processes associated with atmospheric aging that may change composition and surface properties (e.g. Gard et al., 1998; Laskin et al., 2005). Moreover, only a limited amount of particle types can be investigated in a laboratory. Several field studies have been conducted with simultaneous, parallel measurements of chemical composition and CCN activity (Shantz et al., 2008, 2010; Chang et al., 2010); however, in these studies the chemical identity of the $\mathrm{CCN}$ active components is inferred based on the size and chemical composition of the entire aerosol population. Thus, there is a surprisingly lack in direct measurement of CCNC formed droplet composition to date (Osborn et al., 2008; Slowik et al., 2011).

We have coupled a commercially-available CCNC to a counterflow virtual impactor (CVI) in order to form droplets as a function of supersaturation and separate them for subsequent direct analysis. We then evaporate the condensedphase water in order to determine the size and composition of the CCNC droplet residuals using an Aerodyne Research (Billerica, MA) high-resolution-time-of-flight Aerosol Mass Spectrometer (hereafter referred to as AMS for brevity) and the Particle Analysis by Laser Mass Spectrometry (PALMS) instrument. Laboratory studies were conducted on particle types with known critical supersaturations in order to validate this technique. Direct measurements of the effect of composition on $\mathrm{CCN}$ formation were then conducted with atmospheric aerosol particles. To the best of our knowledge this is the first time a commercial CCNC has been coupled to a CVI and mass spectrometer to study $\mathrm{CCN}$-active aerosol chemistry, and we are aware of only one other such instrumental combination using a custom built CCNC (Slowik et al., 2011).

\section{Methodology}

The goal of the instrumental technique described in the following section was to determine the chemical composition and size of those aerosols which formed droplets as a function of supersaturation. A second goal was that droplet formation, inertial separation, and size and composition determination were accomplished with commercially available instruments operating within their typical experimental parameters. The second goal was accomplished with the exception of one experiment utilizing a custom single particle PALMS instrument.

\subsection{Instruments}

A CCNC, commercially available from Droplet Measurement Technologies (Model 200-013, Boulder, CO), was used to activate droplets from incoming aerosol particles as a function of supersaturation from $0.07-1 \%$. A full description of the instrument is available in Roberts and Nenes (2005). For these studies a dual-column CCNC employed although only one column was connected to the CVI for droplet separation and compositional analysis. The total CCNC inlet flow is internally split into a $0.045 \mathrm{lpm}$ sample flow and a $0.45 \mathrm{lpm}$ sheath flow that is filtered to remove particles; thus the concentration of particles entering the column is reduced by a dilution factor of $0.09\left(\cong \frac{0.045 \mathrm{lpm}}{0.45 \mathrm{lpm}+0.045 \mathrm{lpm}}\right)$ relative to initial particle concentration. The particles are passed through a temperature-controlled vertical column with water-coated walls. Supersaturated conditions are produced in the column due to a temperature gradient produced by three differentially heated zones and the fact that water molecules diffuse more 
quickly than heat. The flow regime in the column is assumed to be laminar with a residence time of $\sim 25 \mathrm{~s}$. Once activated, the number and size distribution of droplets (from 0.75 to $10 \mu \mathrm{m}$ diameter) is measured using an integrated optical particle counter (OPC) in the CCNC. We note that the particle count of the integrated OPC is automatically corrected for sheath flow dilution factor of $\sim 0.09$ given above. For example, the OPC readout of $5000 \mathrm{~cm}^{-3}$ corresponds to an estimate of $\sim 455 \mathrm{~cm}^{-3}$ particles passing through the CCNC.

Droplets exiting the CCNC were separated from unactivated particles using a pumped CVI (PCVI) previously described in the literature (Boulter et al., 2006; Kulkarni et al., 2011) and commercially available from Brechtel Manufacturing, Inc. (Model 8100). A PCVI functions by drawing particles into the instrument with a vacuum pump. The use of a pump differentiates a PCVI from traditional CVIs which use the motion of an aircraft or a wind tunnel to cause particles to enter the impactor. The PCVI is therefore a self-contained inertial separation unit that can be used in a laboratory setting (Boulter et al., 2006). A flow of particle-free gas termed the counterflow is directed in a motion opposite the particle flow. In this way the counterflow creates an inertial barrier which stops particles below a specific cut-size so that they are removed by the flow to the pump. The rate of counterflow sets the inertial barrier and thus the cut-size. The counterflow can be varied to set the cut-size although the system pressure and other flows are secondary factors in determining the inertial barrier (Boulter et al., 2006). The counterflow is a portion of the total flow added to the PCVI; the remainder forms an output or "sample flow" into which the particles above the cutsize become entrained (i.e. particles above the cut-size exit the PCVI within a different gas-phase environment than they entered; Boulter et al., 2006). In the case of these studies, the counterflow was particle-free dry research-grade nitrogen $(99.99 \%$ purity). The cut-size was set to allow passage of droplets but not unactivated particles. The dry nitrogen carrier gas caused evaporation of the condensed-phase water on the droplets so that only residual aerosol particles which initially formed the droplets in the CCNC remained in the sample flow.

The AMS has been described in the literature previously (Jayne, 2000; Jimenez et al., 2003; DeCarlo et al., 2008). Briefly, particles entrained in $0.1 \mathrm{lpm}$ of flow are impacted onto a resistively heated ceramic oven. The oven was held at a temperature of $850{ }^{\circ} \mathrm{C}$ when studying PSL particles and at $600^{\circ} \mathrm{C}$ in all other experiments. The AMS lens transmits particles with vacuum aerodynamic diameters of 70 $500 \mathrm{~nm}$ with nearly $100 \%$ efficiency and diameters of 500$2000 \mathrm{~nm}$ with lower, but non negligible efficiency (Jayne, 2000). Bouncing of solid particles from the heater before volatilization may reduce the AMS sampling efficiency further. Non-refractory components (operationally defined as components that vaporize in $\sim 2 \mathrm{~s}$ ) are volatilized on impact and the resultant vapor plume is ionized by electron impact at $70 \mathrm{eV}$. Ions are then orthogonally extracted at $20 \mathrm{kHz}$ into a time of flight mass analyzer and detected after separation on a microchannel plate. For this study, only the higher sensitivity "V" mode of the mass analyzer was employed. Mass spectra are analyzed with standard software as described in the literature to chemically resolve particle components (Allan et al., 2004). For the ambient studies, detection limits for the instrument as operated ( $1 \mathrm{~min}$ averaging) are approximately $0.1,0.03,0.02,0.15 \mu \mathrm{g} \mathrm{m}^{-3}$ for organics, nitrate, sulfate, and ammonium, respectively. A lower effective detection limit can be achieved for certain species, such as PSL particles $\left(0.01 \mu \mathrm{g} \mathrm{m}^{-3}\right.$ nitrate equivalent mass at $\left.\mathrm{m} / \mathrm{z} 104\right)$ by monitoring a single intense peak that has a low background and little interference from other species. In this way, the presence or absence smaller mass concentrations of an individual component can be determined, though quantitatively relating the measured signal of one $\mathrm{m} / \mathrm{z}$ fragment to the concentration of that component in the airstream requires additional calibration steps (see for example Katrib et al., 2004).

PALMS has also been described in the literature previously (Cziczo et al., 2006). Particles in $0.3 \mathrm{lpm}$ of flow are detected as they scatter light from two visible $532 \mathrm{~nm}$ YAG lasers set a known distance apart and this allows for a calculation of aerodynamic diameter. A $193 \mathrm{~nm}$ excimer laser is subsequently triggered to ablate and ionize the components. Positive or negative ions are sent through a reflectron mass spectrometer flight tube and detected as a function of mass. Particle size and chemical composition are thus recorded on the single particle level in situ and in real time. Optical detection and aerodynamic focusing restrict the detectable particle size bounds to $\sim 150-3000 \mathrm{~nm}$, respectively. Within this range all atmospheric aerosol components, from refractory (e.g. black carbon and mineral dust) to semi-volatile (e.g. sulfates and organics), can be resolved. Single particle mass spectrometers such as PALMS are not inherently quantitative due to the different ionization efficiencies of common atmospheric aerosol components. The physical state of the aerosol components also affects the mass spectrum. One example is that different processes are involved in ionizing the same weight percent of an inorganic salt in solution in an aqueous aerosol versus in a crystalline form bound within a mineral dust particle. Collectively, these different ionization thresholds and processes are termed "matrix effects" and limit the use of single particle instruments for quantitation. Trends in ion current (i.e. detector signal) can be used as an indication of relative abundance and particle fractions on the order of $1 \%$ are detectable (Cziczo, 2010 and references therein).

\subsection{Experimental setup}

A schematic of the experimental setup is shown in Fig. 1. Connection from the CCNC to the PCVI is made directly after the CCNC-OPC. The internal chiller and pump of the CCNC are bypassed to direct droplets to the PCVI. A $9.5 \mathrm{lpm}$ particle-free humidified "supplemental flow" was added to the $\sim 0.5 \mathrm{lpm}$ CCNC flow in order to produce the required 


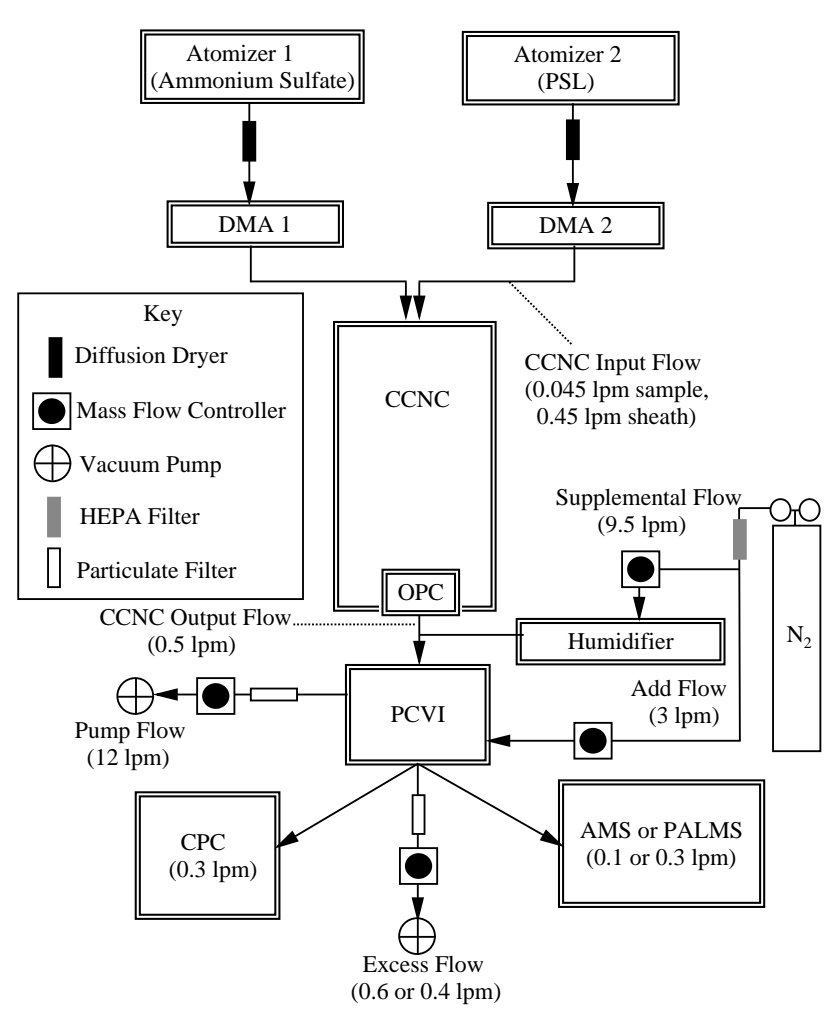

Fig. 1. Schematic of the experimental setup. The diffusion dryer ensured a relative humidity below $5 \%$ upon entry to the DMA.

PCVI input flow, while preventing droplet evaporation. The supplemental flow was humidified by passing it through Nafion tubing (Perma Pure, Toms River, NJ, PD Series) immersed in ultrapure water $(18.2 \mathrm{M} \Omega \mathrm{cm})$. Droplets formed in the CCNC were passed through a $0.34 \mathrm{~m}$ length of stainless tubing with a $4 \mathrm{~mm}$ inner diameter tube in the centerline of a $15 \mathrm{~mm}$ tube containing the supplemental flow. The tubing diameters were chosen to achieve isokinetic mixing of the CCNC output flow and the supplemental flow (i.e. the activated droplets are focused to the centerline of the tubing under laminar flow conditions). The PCVI sample (outlet) flow was $1.0 \mathrm{lpm}$ for all experiments conducted here. The number density of particles in this flow was counted by directing $0.3 \mathrm{lpm}$ to a condensation particle counter (CPC; TSI Inc., Shoreview, MN, model 3775). For experiments where particle size and composition were also measured, either an AMS or PALMS was attached in parallel. The portion of the $1 \mathrm{lpm}$ PCIV outlet flow not consumed by the instruments (the "excess flow") was removed with a vacuum pump.

\subsection{Validation of instrument performance}

Initial tests and calibration of the instrument supersaturation were conducted to validate the performance of the CCNC following the empirical methods described in Rose et al. (2008) and Shilling et al. (2007). Specifically, ammonium sulfate
( $>99 \%$ purity, Sigma) was dissolved in $18.2 \mathrm{M} \Omega \mathrm{cm}$ ultrapure water, the 0.1 weight percent solution was atomized (Atomizer model 3076; TSI Inc., Shoreview, MN), and passed through a differential mobility analyzer (DMA; TSI Inc., Shoreview, MN, Model 3080) to produce a monodisperse particle stream. Calibrations were performed with monodisperse particle sizes ranging from $50-100 \mathrm{~nm}$. Activation curves were generated by scanning the CCNC supersaturation $(0.07$ to $0.75 \%)$ while comparing the number of activated droplets counted by the CCNC-OPC to the total number of particles counted by a CPC (TSI 3775). By following Rose et al. (2008), the calibrated supersaturation was then calculated from the measured critical supersaturation $\left(S_{\text {crit }}\right.$; where $50 \%$ of the single charged particles are $\mathrm{CCN}$ active), the known particle diameter $(D)$, and the literature value of the ammonium sulfate hycroscopicity parameter $(\kappa$ of 0.61 ; Petters and Kreidenweis, 2007). Specifically, to determine the calibrated saturation, the portion of the activation spectrum corresponding to the singly charged particles was fit with the formula:

$\left(\frac{S_{\text {crit }}}{100}+1\right)=\exp \left(\frac{4 A^{3}}{27 \cdot \kappa \cdot D^{3}}\right)^{\frac{1}{2}}$

with

$A=\frac{4 \sigma_{\mathrm{w}} M_{\mathrm{w}}}{R T \rho_{\mathrm{w}}}$

where $\sigma_{\mathrm{w}}$ is the surface tension of water $\left(0.072 \mathrm{~J} \mathrm{~m}^{-2}\right), M_{\mathrm{w}}$ and $\rho_{\mathrm{w}}$ the water molecular weight $\left(0.018 \mathrm{~kg} \mathrm{~mol}^{-1}\right)$ and density of water $\left(997 \mathrm{~kg} \mathrm{~m}^{-3}\right), R$ the universal gas constant $\left(8.3 \mathrm{~J} \mathrm{~K}^{-1} \mathrm{~mol}^{-1}\right), T$ the air temperature $\left(25^{\circ} \mathrm{C}\right.$ for laboratory measurements), and $\kappa$ the hygroscopicity of the aerosol particles (Petters and Kreidenweis, 2007). Calibrations before, during, and after the experiments agreed in saturation to within $\pm 0.04 \%$ indicating that the $\mathrm{CCNC}$ was stable during the entire project and validating the performance of the CCNC.

Figure 2 shows the measured activation curves for the test particle species employed in CCNC-CVI validation experiments. Modeled CCN activation curves derived from the $\kappa$-Köhler model for ammonium sulfate (assuming $\kappa$ of 0.61 at $25^{\circ} \mathrm{C}$ ) and ammonium nitrate (minimum $99.0 \%$, SigmaAldrich; $\kappa$ of 0.67 at $25^{\circ} \mathrm{C}$ ) are also plotted (Petters and Kreidenweis, 2007). Polystyrene latex (PSL) spheres (Duke Scientific, Palo Alto, CA) and adipic acid (99.6-101.0\%, Riedel-de Haën) were specifically chosen for a surrogate of hydrophobic organics and secondary organic aerosol ( $\kappa$ of 0.096; Kreidenweis and Petters, 2007), respectively. We note that previous observations suggest that $\kappa$-Köhler theory is applicable to atmospheric aerosol that is characterized by $0.1<\kappa<0.9$ (Petters and Kreidenweis, 2007). Since hygroscopicity parameters of adipic acid and PSL are $<0.1$ due to their solubility-limitation $\left(V_{\text {solute }} / V_{\text {water }}<0.1\right), \kappa$-Köhler 


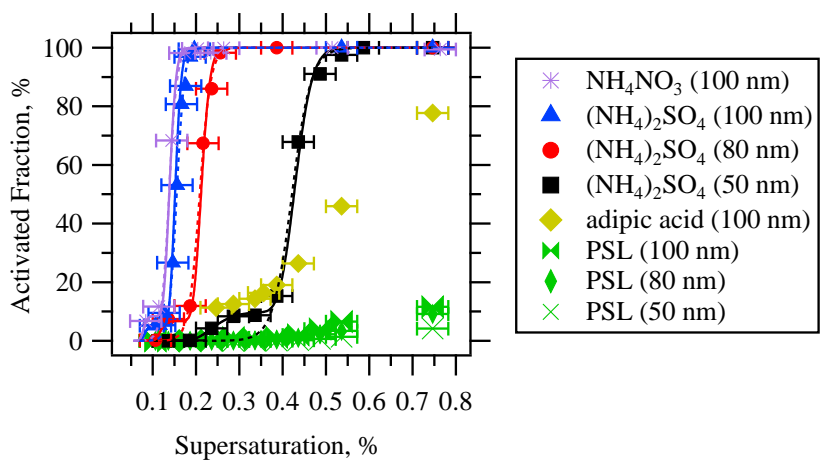

Fig. 2. Fraction of aerosols active as $\mathrm{CCN}$ as a function of supersaturation. The size and composition of the aerosol is differentiated by the shapes given in the legend. Dashed lines represent sigmoid fits to the single charged portions of the activation curves following Rose et al. (2008). Solid lines represent activation model of single and doubly charged components. The $\mathrm{x}$-axis error bar represents $\Delta S$ of $\pm 0.04 \%$.

model for these compounds are not shown in Fig. 2 (Petters et al., 2009b). The activated fraction appearing as a plateau at lower supersaturations corresponded to larger, doubly charged particles with an equivalent mobility diameter as the single charged particles (e.g. selecting a mobility diameter of $80 \mathrm{~nm}$ in the DMA results in transmission of particles with nominal geometric diameters of $80 \mathrm{~nm}$ and $117 \mathrm{~nm}$ ). The size distributions of singly and doubly charged particles were measured by the SMPS. It should be noted that higher orders of multiply charged particles than +2 charges were neglected due to their small population in this study.

The droplet size distribution produced as a function of supersaturation for ammonium sulfate particles was also determined using the CCNC-OPC (Fig. 3). PSL spheres were produced in the same manner after dispersion in $18.2 \mathrm{M} \Omega$ MilliQ water. Note that, as shown in Fig. 2, PSLs are significantly less $\mathrm{CCN}$ active than ammonium sulfate at a given size throughout the range of supersaturations considered here.

\section{Results and discussion}

\subsection{Laboratory studies}

Two validation experiments were conducted. First, monodisperse ammonium sulfate particles were produced and exposed to a variety of supersaturations in the CCNC and directed to the PCVI. A PCVI cut-size of $\sim 2.5 \mu \mathrm{m}$ was set by using a supplemental flow of $9.5 \mathrm{lpm}$ and a counterflow of $3.0 \mathrm{lpm}$. As shown in Fig. 3, droplets of greater than $3 \mu \mathrm{m}$ are produced for supersaturations of $>0.5 \%$. Figure 4 shows the output particle number density in the PCVI output flow; no particles were transmitted for a supersaturation of $0.25 \%$ whereas at $0.5 \%$ droplets were detected.

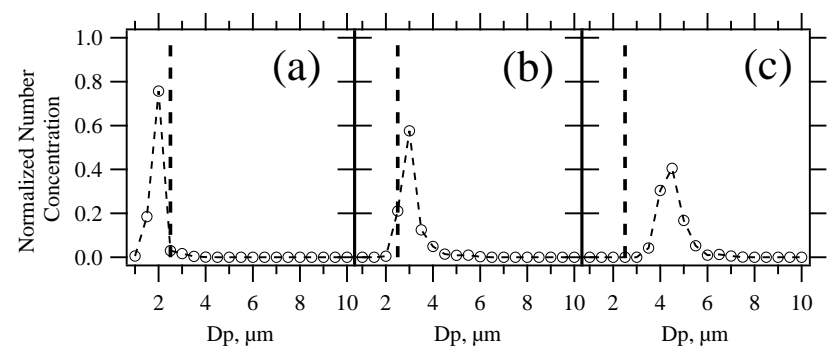

Fig. 3. Droplet size distribution as a function of supersaturation, (a) $0.25 \%$, (b) $0.5 \%$, and (c) $0.75 \%$, for ammonium sulfate. Note that vertical extension of dashed line in each panel represents the $D_{50}$ cut-size of $\sim 2.5 \mu \mathrm{m}$ diameter for the PCVI.

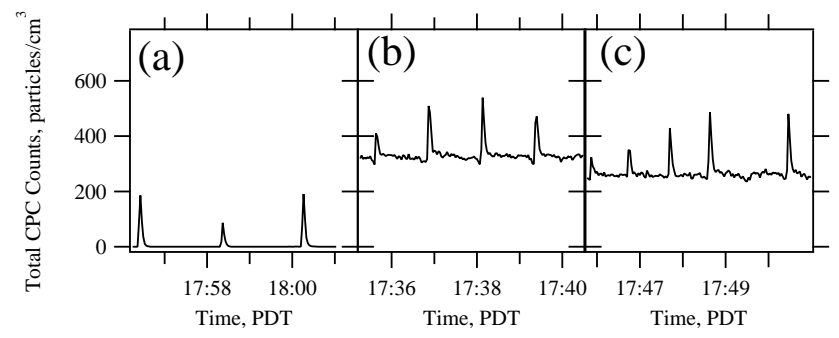

Fig. 4. Transmitted particle number density after the PCVI as a function of time for various supersaturations. During Period (a) the droplets remained below the cut-size and no particles were transmitted (supersaturation $0.25 \%$ ). During Period (b) the ammonium sulfate particles activated into droplets larger than the cut-size $(0.5 \%)$. During Period (c) droplets grew to a size where impaction losses increased over those in Period (b) (0.75\%; Kulkarni et al., 2011). See Fig. 3 for relevant droplet sizes.

Assuming all the particles are fully activated into droplets larger than the PCVI cut-size the number density downstream of PCVI, $\mathrm{CCN}_{\mathrm{CPC}}\left(\mathrm{cm}^{-3}\right)$ can be estimated as:

$\mathrm{CCN}_{\mathrm{CPC}}=\mathrm{CCN}_{\mathrm{OPC}} \cdot \delta_{\mathrm{CCNC}} \cdot \delta_{\mathrm{PCVI}} \cdot \varepsilon_{\mathrm{PCVI}} \cdot \tau$

where $\mathrm{CCN}_{\mathrm{OPC}}$ is the $\mathrm{CCN}$ concentration measured by the CCNC-OPC $\left(\mathrm{cm}^{-3}\right), \delta_{\mathrm{CCNC}}$ is the sample flow dilution factor inside the CCNC $\left(0.09 \cong \frac{0.045 \mathrm{lpm}}{0.45 \mathrm{lpm}+0.045 \mathrm{lpm}}\right)$ which accounts for the ratio of the sample to sheath flow, $\delta_{\mathrm{PCVI}}$ is the sample flow dilution factor prior to entering the PCVI $\left(0.05=\frac{0.5 \mathrm{lpm}}{9.5 \mathrm{lpm}+0.5 \mathrm{lpm}}\right)$ which accounts for the ratio of the sample to supplemental flow, $\varepsilon_{\mathrm{PCVI}}$ is the PCVI enhancement factor $\left(10=\frac{101 \mathrm{pm}}{1 \mathrm{lpm}}\right)$ which accounts for the ratio of sample to input flow, and $\tau$ is the PCVI efficiency (0.75) which accounts for a $25 \%$ particle loss in the PCVI (Kulkarni et al., 2011). Equation (3) implies that the total transmittance factor $\left(0.034 \cong \frac{\mathrm{CCN}_{\mathrm{CPC}}}{\mathrm{CCN}_{\mathrm{OPC}}}\right)$ for this DMT CCNC-PCVI experiment results from a combination of the dilution factor $\left(0.045=\delta_{\mathrm{CCNC}} \cdot \delta_{\mathrm{PCVI}} \cdot \varepsilon_{\mathrm{PCVI}}\right)$, which is the ratio of $\mathrm{CCN}$ incoming flow of $0.045 \mathrm{lpm}$ to the PCVI output flow of $1 \mathrm{lpm}$, and $\tau$. Particle numbers are explicitly reduced by the flow dilution inside the $\mathrm{CCNC}$ while the perceived dilution by the 
PCVI makeup flow is largely offset because the PCVI acts as a particle concentrator (Kulkarni et al., 2011).

During the period of time given in Fig. $4 \mathrm{~b}$ the average $\mathrm{CCN}$ concentration measured by the CCNC was $9365 \mathrm{~cm}^{-3}$. After the PCVI, we measure particle concentrations of $331 \mathrm{~cm}^{-3}$, which compares well with expected number of particles $\left(319 \mathrm{~cm}^{-3}\right)$ calculated as described above. Thus, the data indicate that $\sim 100 \%$ activation was achieved and that droplets were collected and transferred to the PCVI with no measurable loss or coagulation. We note that the effect of condensational depletion of water vapor due to the high number of CCNC may reduce the effective saturation in the CCNC column; however, it should not affect the compositional analysis of the droplet residual (Lathem and Nenes, 2011). Two features of the transmission curve are noteworthy: (1) when droplets were produced at $0.75 \%$ supersaturation, a lower number density was observed in the output flow. This is due to increased impaction losses for larger particles as described in Kulkarni et al. (2011). (2) Periodic spikes are apparent in the CPC data. Visual inspection showed that these spikes were due to occasional "sputtering" of water that is collected when humidified air condenses, collects, and finally drips in a low-flow eddy region in the pump-flow ports of the CVI. These large droplets presumably shatter when they hit the counterflow because they have little initial velocity. These sputtering remnants likely contain a small amount of residual material, but were not detectable by either the AMS or the PALMS, presumably due to their small size and mass upon drying.

In the second validation experiment two particulate flows, one of ammonium sulfate $(0.00076 \mathrm{M})$ and the other of PSLs (100 nm diameter), were produced by two identical atomizers. Two identical DMAs selecting $100 \mathrm{~nm}$ diameter particles for ammonium sulfate and PSL were used to produce monodisperse flows of the same rate that were combined. Three periods were investigated (Fig. 5). During "Period I" the particle number density and ammonium sulfate and PSL signal exiting the DMAs (i.e. before the CCNC and PCVI) was determined (panel Ia). The average mass spectrum during this period is given in panel Ib. During Period II the combined particle flow was passed through the CCNC and PCVI when the saturation, $0.25 \%$, was not sufficient to form droplets that have a size large enough to pass the PCVI from either particle type (see Figs. 2 and 3). Panels IIa and b are analogous to Ia and b but note that no particles are transmitted and only noise is observed in the mass spectrum. During Period III the saturation, $0.75 \%$, was sufficient to activate droplets of ammonium sulfate to a size large enough to pass the PCVI and particles are detected in the sample flow (panel IIIa). The measured mass concentrations of the sulfate recovered from the activated $\mathrm{CCN}$ droplets (i.e. in Fig. 5, panel IIIa) agrees well with the theoretically calculated mass concentration after accounting for the dilution factors and the PCVI transmission factor given above. Conversely, PSL spheres were not expected to activate (see Figs. 2 and 3); at

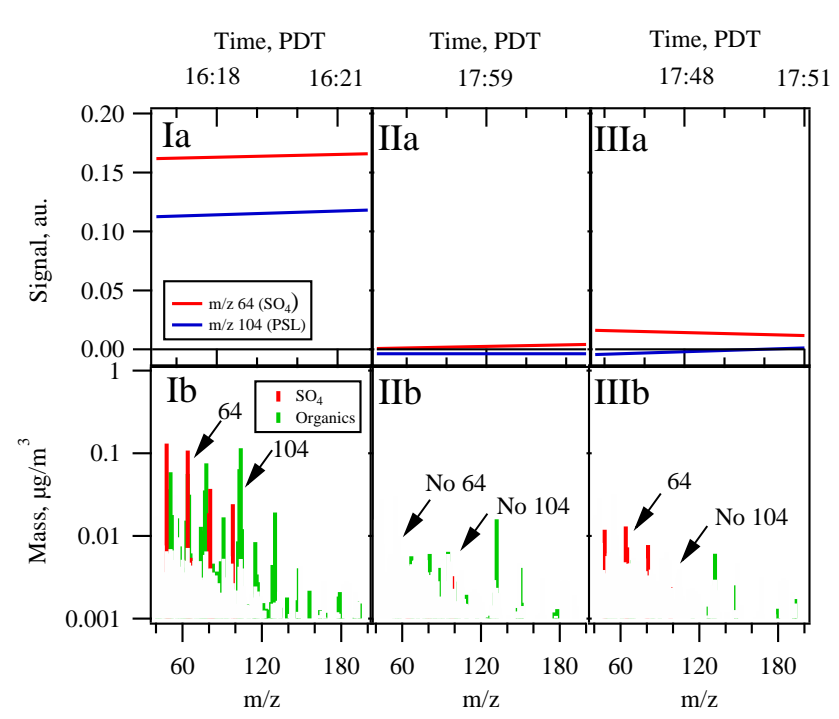

Fig. 5. Aerosol concentration and composition for experiments where ammonium sulfate and PSL spheres were externally mixed. Panel (Ia) is the time series of sulfate and PSL mass spectra signal before the CCNC and PCVI. The AMS average mass spectrum during this period is given in (Ib). (IIa) is the same quantities as in (Ia) but after the CCNC and PCVI at $0.25 \%$ saturation when the saturation was not sufficient to form droplets that have a larger size than the PCVI cut-size from either particle type (see Figs. 2 and 3). The concurrent spectrum is given in (IIb). Panel (III) shows that the saturation $(0.75 \%)$ was sufficient to activate droplets from ammonium sulfate and the formed droplets were large enough to pass the PCVI whereas PSL spheres did not activate (see Figs. 2 and 3). Note that only ammonium sulfate, and not PSL signal, is evident in (IIIa) and the mass spectrum in (IIIb).

$0.75 \%$ supersaturation and the AMS signal characteristic of the PSL particles is indeed below the detection limit (panels IIIa and b). Thus, for this model system, we were able to separate and quantify $\mathrm{CCN}$ active and inactive aerosol particles. The average mass spectra of ammonium sulfate and PSL measured by the PALMS are shown in Supplement Fig. S1.

To demonstrate our ability to separate more atmospherically relevant aerosol populations using this technique, we conducted a similar calibration experiment utilizing an external mixture of ammonium nitrate $(0.0015 \mathrm{M})$ and adipic acid $(0.00082 \mathrm{M})$. As before, an external mixture of monodisperse ammonium nitrate $(100 \mathrm{~nm}$ mobility diameter) and adipic acid $(100 \mathrm{~nm}$ mobility diameter) particles were generated, mixed, and passed into the CCNC-PCVI setup. Results for this experiment are shown in Fig. 6. Period I shows AMS analysis of the particle mixture entering the CCNC. During Period II the combined particle flow was passed through the CCNC and PCVI when the saturation, $0.5 \%$, was sufficient to activate droplets from both particle types (see Fig. 2). However, as indicated by the AMS signal trace, only one population of droplets (ammonium nitrate) grow to sufficient 

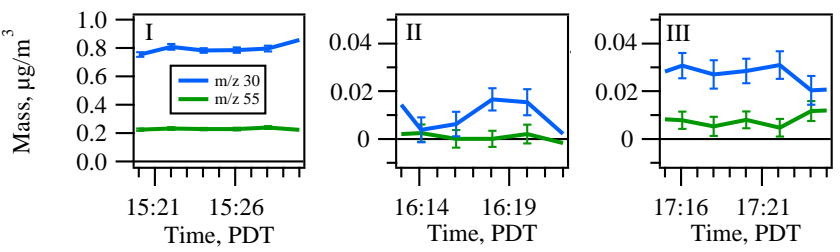

Fig. 6. Aerosol concentration and composition for experiments where $100 \mathrm{~nm}$ ammonium nitrate $(0.0015 \mathrm{M})$ and $100 \mathrm{~nm}$ adipic acid $(0.00082 \mathrm{M})$ were externally mixed. Panel (I) is the time series of sulfate and adipic acid mass spectra signal before the CCNC and PCVI. Panel (II) is the same quantities as in (I) but after the CCNC and PCVI at $0.5 \%$ saturation. Although the saturation was sufficient to activate droplets from ammonium nitrate and adipic acid, the formed droplets of adipic acid were not large enough to pass the PCVI. Panel (III) shows that the high saturation (1\%) was sufficient to activate droplets from ammonium nitrate and adipic acid and the formed droplets of both particle types were large enough to pass the PCVI. Note that only ammonium nitrate, and not adipic acid signal, is evident in (IIa) and the mass spectrum in (IIb).

size to pass through the PCVI. During Period III the saturation, $1 \%$, was sufficient to activate droplets of both particle types to a size large enough to pass the PCVI and particles are detected in the sample flow (panel III). Thus, we were able to separate more atmospherically relevant organic species from inorganic salts, enhancing the potential of this technique to reveal $\mathrm{CCN}$-active aerosol composition and mixing state.

\subsection{Atmospheric measurements}

After characterizing the CCNC-PCVI apparatus, we sample the ambient air in the semi-urban town of Richland, WA (home to the Pacific Northwest National Laboratory) to gain insight into the effect of composition on CCN formation. For experiments with the AMS, ambient particles were exposed to supersaturated condition in the CCNC and droplet residual particles were passed to the AMS downstream of the PCVI. Ambient AMS measurements were also conducted immediately before and after the experiment with the CCNC and PCVI. As illustrated in Fig. 7, the time series of organic and inorganic mass were observed from $\sim 09: 30$ to 12:00 Pacific Daylight Time (PDT) on 20 October 2010. The ambient temperature was $\sim 13^{\circ} \mathrm{C}$ with partly cloudy skies and moderate particle loadings (ambient particle concentration $\sim 10000$ particles $\mathrm{cm}^{-3}$ ) throughout the experiment. A series of supersaturations $(0.25 \%, 0.4 \%$, and $0.75 \%)$ in the $\mathrm{CCNC}$ were employed. A supersaturation of $0.4 \%$ produced 2255 droplets $\mathrm{cm}^{-3}$ (>98\% activation) and 76 residual particles $\mathrm{cm}^{-3}$ in the flow passed to the AMS.

When observing ambient particles, composition derived from the $\mathrm{V}$ mode of AMS measurements was dominated by organics and ammonium nitrate with a small ammonium sulfate contribution (Fig. 7, panels I and III). When sampling behind the PCVI (Fig. 7, panel II), dilution of aerosol parti-

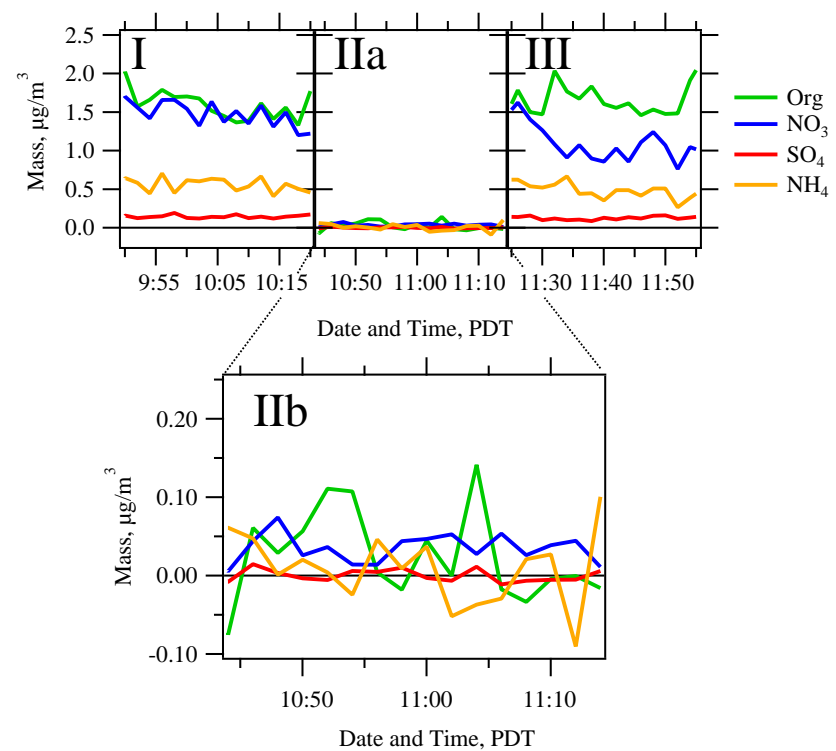

Fig. 7. Time series of organic and inorganic mass determined by AMS measurements. Period (I) is ambient data. Period (II) is the mass measurement after the CCNC and PCVI immediately after Period (I). Period (III) is ambient data immediately after Period (II). Note that Fig. 6, (IIa) has a consistent mass scale with (I) and (III), and Fig. 6, (IIb) has a $10 \times$ mass scale.

cles in the CCNC-PCVI reduced the ammonium and sulfate signals to below the AMS detection limit regardless of their activation in the CCNC. We see positive evidence that particles containing nitrate activated in the CCNC. Based on the CCNC-PCVI dilution ratio, the organic signal of activated particles is expected to be near the AMS detection limit, assuming all organic containing particles activated. AMS observations show the organic signal hovering around the detection limit (Fig. 7, panel IIb). Therefore, the role of organics in CCN activation is unclear on this particular day and AMS speciation of the $\mathrm{CCN}$ active and inactive droplets is inconclusive. In the next section of the manuscript, we present improvements to the current experimental setup that would increase the number of particles transmitted to the AMS, possibly overcoming the signal-to-noise limitations observed in this study.

Experiments with the PALMS instrument were conducted in the same manner as for the AMS. An exemplary negative polarity mass spectrum of a residual particle of a droplet formed in the CCNC and separated from unactivated particles in the PCVI is shown in Fig. 8a. Peaks attributed to different species (e.g. sulfate, nitrate and organic) are specified. Data were collected as follows: 1000 positive and negative mass spectra of ambient particles were collected over $\sim 10$ min starting at 16:00 PDT on 9 November 2010. The ambient temperature was $\sim 5^{\circ} \mathrm{C}$ with overcast skies and occasional drizzle and these conditions continued throughout the experiment. Ambient sampling was immediately 

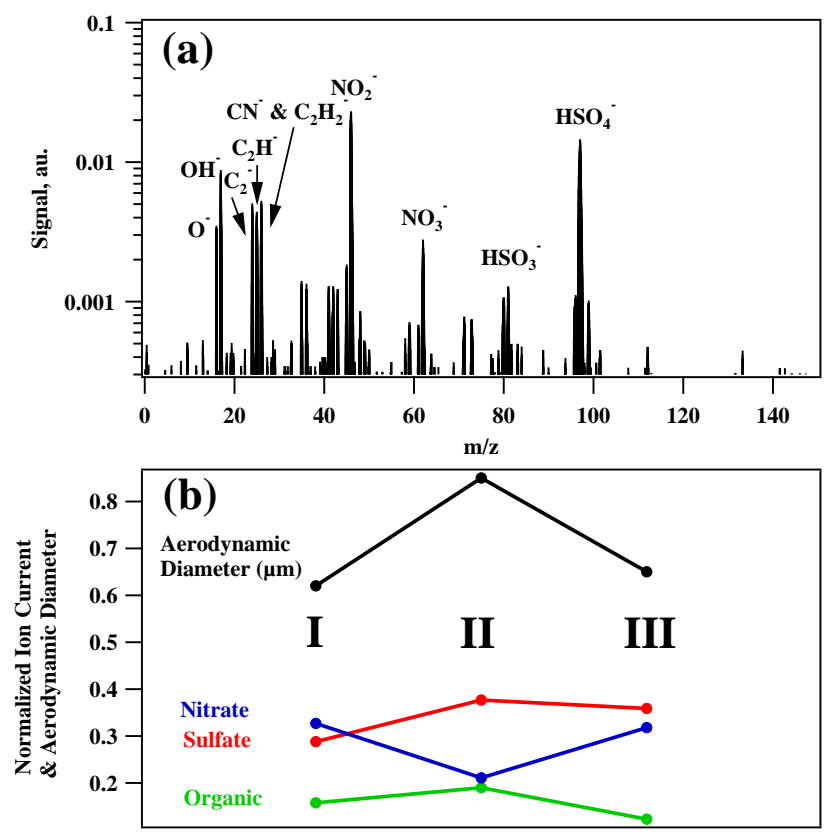

Fig. 8. Negative polarity mass spectrum of a $\mathrm{CCN}$ residual using the PALMS instrument (a). Sulfate, nitrate and organic peaks are identified. Time series averages of aerodynamic diameter and sulfate, nitrate and organic signal (b). Period I is ambient data. Period II is from mass spectra after the CCNC and PCVI immediately after Period I. Period III is ambient data immediately after Period II. See text for details.

followed by analysis of drop residue by connecting PALMS after the CCNC and PCVI for a period of $30 \mathrm{~min}$. This resulted in the acquisition of 225 positive and 350 negative mass spectra. This period was immediately followed by collection of an additional 1000 positive and negative mass spectra. The CCNC was set at $0.5 \%$ saturation with respect to water producing an average of 500 droplets $\mathrm{cm}^{-3}$; this resulted in 29 residual particles $\mathrm{cm}^{-3}$ in the flow passed to the PALMS instrument.

Average particle aerodynamic diameter and normalized signal attributed to sulfate, nitrate and organic are presented in Fig. 8b. The normalized signal presented in Fig. 8 is a count of detected ions and this is dependent on the specific particle matrix. As described in the instrumental section, PALMS provides universal detection of atmospheric particle components at a qualitative level. Trends of composition are given for the ambient and CCNC-PCVI periods. Period I is the initial ambient data sample, Period II is while PALMS was connected to the CCNC and PCVI, and Period III is the final ambient sample. The peak analysis corresponds to the subset of negative polarity mass spectra acquired whereas the size information uses all mass spectra. The droplet residual material is somewhat larger than the ambient aerosol size although these correspond to the subset of $\mathrm{CCN}$ residuals within the PALMS size range. The total of all mass spec- tral peaks is 1 with the fraction attributed to sulfate, nitrate and organic presented in Fig. $8 \mathrm{~b}$ for each time period; note that these species make up the majority, from $73-80 \%$, of the total ion current produced in each period. Sulfate is slightly enhanced in the residual particles whereas nitrate is slightly reduced. Organic components do not display a clear trend.

\section{Future studies}

We have demonstrated that droplets formed within a commercially-available CCNC chamber can be inertially separated using a PCVI. The composition of the droplet residue, after evaporation of condensed phase water, was determined with either an AMS or the PALMS instrument. In a laboratory setting, particle concentrations are often sufficiently high that AMS detection of droplet residuals is possible, even after particle dilution and loss through the apparatus. However, when sampling ambient aerosol, AMS detection of the chemical composition of the droplet residuals was limited by low signal levels and single particle mass spectrometers (e.g. PALMS) were generally better suited to the analysis. In the following section, we present a series of improvements to the current apparatus that would improve particle transmission through the apparatus and thus extend the conditions under which AMS analysis of the droplet residuals would be successful.

\subsection{Modification to the $\mathrm{CCNC}$}

First, the output of a single column of the two within the DMT Model 200 CCNC instrument was used as input to the PCVI. This allows for the use of the second column to scan ambient $\mathrm{CCN}$ concentration. In cases of low $\mathrm{CCN}$ number (i.e. either low aerosol loading or when a low supersaturation is utilized) the output of both columns could be combined as input to the PCVI. It is noteworthy that this would not change the absolute concentration of droplets but would offer a means to double the number for subsequent separation. We attempted this modification but found it actually reduced the number of particles transmitted through the PCIV (i.e. a total transmittance factor from 0.034 to 0.006 ). We attribute the reduced transmission to increased particle loss prior to the PCVI, likely caused by difficulty in mixing the airstreams from the two CCNC columns.

Second, the CCNC sample flow could be increase and/or the sheath flow decreased. This modification would result in a higher concentration of droplets in the CCNC output flow at the expense of uniformity and certainty in the CCNC supersaturation field. We expect that that some of the uncertainty could be mitigated by careful calibrations. 


\subsection{Modification to the PCVI}

These studies were undertaken without significant changes to the PCVI from the previous literature (Boulter et al., 2006; Kulkarni et al., 2011). No significant changes were made because the literature cut-points were in agreement with those desired for the CCNC studies. We note that the two possible modifications to the PCVI would improve its performance. First, it would be desirable to lower the cut-point of the PCVI to near $1 \mu \mathrm{m}$ such that activated droplets would grow to sufficient size during their residence time in the CCNC column to be transmitted thought the PCVI. This would require determination and testing with different PCVI flows and pressures. Second, the PCVI could be designed such that the sample flow exactly matches the flow requirements of the downstream instrumentation. In this way, particle mass is not lost in the excess flow stream. This modification would also require redesign of the PCVI.

\subsection{Simultaneous mass spectrometry}

The ability of the AMS to quantitatively determine chemical composition to particle sizes near the activation threshold of the CCNC is highly complementary to the ability of PALMS to universally detect atmospheric aerosol components on a particle by particle basis. In the future we suggest these techniques be used simultaneously. As an example, we observed periods where the number of $\mathrm{CCN}$ residuals was too low to result in an AMS signal but during these periods PALMS would produce qualitative single particle spectra. The abundance of refractory aerosols acting as CCN (e.g. mineral dust, sea salt and soot) would not be evident to the AMS but could be determined by PALMS. Conversely, AMS is required to probe the composition of CCN residuals below the PALMS size threshold and to provide a quantitative determination of composition. A full description of atmospheric $\mathrm{CCN}$ would benefit from simultaneous application of both techniques.

\section{Conclusions}

We have connected a commercial CCN chamber to a PCVI in order to separate droplets from unactivated interstitial aerosol. The number of residual particles compared favorably with the droplets produced in the $\mathrm{CCN}$ chamber, with particle losses on the order of $25 \%$, consistent with what has been observed previously using PCVIs. A series of validation experiments were performed. First, various supersaturations were used to produce droplets of different sizes. Only when droplets larger than the cut-size of the PCVI were formed were residual particles observed in the sample flow. This verified that only droplets with sufficient size passed through the counterflow virtual impactor for subsequent analysis. Second, an external mixture of ammonium sulfate and PSL monodisperse particles was also exposed to a supersaturation which would activate only ammonium sulfate but not the PSLs. The mass spectrum observed with an AMS after separation indicated only ammonium sulfate, validating separation of droplets from unactivated particles. Finally, we successfully demonstrated that the CCNC-PCVI apparatus was able to separate an external mixture of ammonium nitrate particles and soluble organic (adipic acid) particles with similar CCN activity as secondary organic aerosol particles. To our knowledge this is the first time a commercial DMT CCN chamber has been coupled to a PCVI and mass spectrometer and we are aware of only one other such instrumental combination using a custom CCN chamber (Slowik et al., 2011).

Two mass spectrometers were then used for ambient sampling. An AMS, which provides a quantitative measurement of non-refractory aerosol components of $\sim 70-500 \mathrm{~nm}$ diameter particles, showed little chemical differentiation between ambient particles and the subset that were activated in the CCNC. However, particle loadings were relatively low and dilution from the CCNC-PCVI apparatus alone was expected to reduce the signal level of ammonium, sulfate, and organics to near or below the AMS detection limit. For this particular day, particles containing ammonium nitrate were clearly observed to activate in the $\mathrm{CCNC}$, however the role of the other species in activation remains unclear. One key limitation of this technique was that sufficient particle mass loading had to be present in the sample flow for the AMS to acquire meaningful data. Because separation of droplets by the CCNC-PCVI requires that the ambient aerosol concentrations be diluted by a factor of $\sim 30$, ambient particle mass loadings of $1-5 \mu \mathrm{g} \mathrm{m}^{-3}$ (depending on particle composition) are required to chemically differentiate particle CCN activity by the AMS. The AMS coupled with the PCVI can provide a quantitative measurement of bulk aerosol composition with high time resolution, however, these results suggest that PCVI-AMS combination may not be the optimal technique to observe the influence of composition on cloud droplet formation in the absence of relatively high particle mass loadings. The PALMS instrument, which provides universal component detection on a single particle basis but only on a qualitative level from $\sim 150-3000$ nanometers diameter, was used during a different sampling period. PALMS showed a slight increase in the size of particles which were activated as droplets. Slight chemical differences were observed with a small enhancement of sulfate and decrease in nitrate observed in the droplet residuals.

These two mass spectrometers proved to be complementary instruments. The AMS was able to probe particle sizes near the activation threshold and produced quantitative data. PALMS was able to universally detect aerosol components, including mineral dust and black carbon, and acquired single particle data even when only a few droplet residuals per $\mathrm{cm}^{3}$ were present in the sample flow. We believe that for most ambient sampling use of both techniques will be required to fully characterize the effect of aerosol composition on cloud droplet formation. 


\section{Supplementary material related to this article is available online at: http://www.atmos-meas-tech.net/4/2333/2011/ amt-4-2333-2011-supplement.pdf.}

\section{Copyright statement}

The author's copyright for this publication is transferred to Battelle Memorial Institute.

Acknowledgements. Funding for this work was provided by the Pacific Northwest National Laboratory Aerosol Climate Initiative and Goethe-University Frankfurt am Main. We acknowledge the assistance of Joachim Curtius in facilitating Monika Kohn's participation on this project. The authors wish to thank Karl Froyd for assistance with the mass spectrometer and the reviewers for their suggestions, in particular those which motivated the expanded description of this technique and the future studies section. We also wish to thank Gourihar Kulkarni, Jay Slowik and Jon Abbatt for useful discussions.

Edited by: P. Laj

\section{References}

Albrecht, B. A.: Aerosols, cloud microphysics and fractional cloudiness, Science, 245, 1227-1230, 1989.

Allan, J. D., Delia, A. E., Coe, H., Bower, K. N., Alfarra, M. R., Jimenez, J. L., Middlebrook, A. M., Drewnick, F., Onasch, T. B., Canagaratna, M. R., Jayne, J. T., and Worsnop, D. R.: A generalised method for the extraction of chemically resolved mass spectra from aerodyne aerosol mass spectrometer data, J. Aerosol Sci., 35, 909-922, 2004.

Asa-Awuku, A., Engelhart, G. J., Lee, B. H., Pandis, S. N., and Nenes, A.: Relating CCN activity, volatility, and droplet growth kinetics of $\beta$-caryophyllene secondary organic aerosol, Atmos. Chem. Phys., 9, 795-812, doi:10.5194/acp-9-795-2009, 2009.

Boulter, J. E., Cziczo, D. J., Middlebrook, A. M., Thomson, D. S., and Murphy, D. M.: Design and performance of a pumped counterflow virtual impactor, Aerosol Sci. Tech., 40, 969-976, 2006.

Chang, R. Y.-W., Slowik, J. G., Shantz, N. C., Vlasenko, A., Liggio, J., Sjostedt, S. J., Leaitch, W. R., and Abbatt, J. P. D.: The hygroscopicity parameter $(\kappa)$ of ambient organic aerosol at a field site subject to biogenic and anthropogenic influences: relationship to degree of aerosol oxidation, Atmos. Chem. Phys., 10, 50475064, doi:10.5194/acp-10-5047-2010, 2010.

Cziczo, D. J.: Atmospheric aerosol analysis by laser ionization, in: The Encyclopedia of Mass Spectrometry Vol. 5, edited by: Gross, M. L., Carioli, R. M., Beauchemin, D., and Matthews, D. E., Elsevir, Amsterdam, Netherlands, 2010.

Cziczo, D. J., Thomson, D. S., Thompson, T., DeMott, P. J., and Murphy, D. M.: Aerosol mass spectrometry studies of ice nuclei and other low number density particles, Int. J. Mass Spectrom., 258, 21-31, 2006.

DeCarlo, P. F., Dunlea, E. J., Kimmel, J. R., Aiken, A. C., Sueper, D., Crounse, J., Wennberg, P. O., Emmons, L., Shinozuka, Y., Clarke, A., Zhou, J., Tomlinson, J., Collins, D. R., Knapp, D.,
Weinheimer, A. J., Montzka, D. D., Campos, T., and Jimenez, J. L.: Fast airborne aerosol size and chemistry measurements above Mexico City and Central Mexico during the MILAGRO campaign, Atmos. Chem. Phys., 8, 4027-4048, doi:10.5194/acp8-4027-2008, 2008.

Dusek, U., Frank, G., Hildebrandt, L., Curtius, J., Schneider, J., Walter, S., Chand, D., Drewnick, F., Hings, S., Jung, D., Borrmann, S., and Andreae, M. O.: Size matters more than chemistry for cloud-nucleating ability of aerosol particles, Science, 312, 1375-1378, 2006.

Gard, E. E., Kleeman, M. J., Gross, D. S., Hughes, L. S., Allen, J. O., Morrical, B. D., Fergenson, D. P., Dienes, T., Galli, M. E., Johnson, R. J., Cass, G. R., and Prather, K. A.: Direct observation of heterogeneous chemistry in the atmosphere, Science, 279, 1184-1187, 1998.

Jayne, J. T., Leard, D. C., Zhang, X. F., Davidovits, P., Smith, K. A., Kolb, C. E., and Worsnop, D. R.: Development of an aerosol mass spectrometer for size and composition analysis of submicron particles, Aerosol Sci. Tech., 33, 49-70, 2000.

Jimenez, J. L., Jayne, J. T., Shi, Q., Kolb, C. E., Worsnop, D. R., Yourshaw, I., Seinfeld, J. H., Flagan, R. C., Zhang, X., Smith, K. A., Morris, J., and Davidovits, P.: Ambient aerosol sampling with an aerosol mass spectrometer, J. Geophys. Res., 108, 8425, doi:10.1029/2001JD001213, 2003.

Katrib, Y., Martin, S. T., Hung, H.-M., Rudich, Y., Zhang, H., Slowik, J. G., Davidovits, P., Jayne, J. T., and Worsnop, D. R.: Products and mechanisms of ozone reactions with oleic acid for aerosol particles having core-shell morphologies, J. Phys. Chem. A, 108, 6686-6695, 2004.

King, S. M., Rosenoern, T., Shilling, J. E., Chen, Q., and Martin, S. T.: Increased cloud activation potential of secondary organic aerosol for atmospheric mass loadings, Atmos. Chem. Phys., 9, 2959-2971, doi:10.5194/acp-9-2959-2009, 2009.

Köhler, H.: The nucleus in and the growth of hygroscopic droplets, T. Faraday Soc., 32, 1152-1161, doi:10.1039/tf9363201152, 1936.

Kulkarni, G., Pekour, M., Afchine, A., Murphy, D. M., and Cziczo, D. J.: Comparison of experimental and numerical studies of the performance characteristics of a pumped counterflow virtual impactor, Aerosol Sci. Tech., 45, 382-392, 2011.

Laskin, A., Wietsma, T. W., Krueger, B. J., and Grassian, V. H.: Heterogeneous chemistry of individual mineral dust particles with nitric acid: A combined CCSEM/EDX, ESEM, and ICP-MS study, J. Geophys. Res., 110, D10208, doi:10.1029/2004JD005206, 2005.

Lathem, T. L. and Nenes, A.: Water vapor depletion in the DMT continuous-flow $\mathrm{CCN}$ chamber: Effects on supersaturation and droplet growth, Aerosol Sci. Tech., 45, 604-615, 2011.

Lohmann, U. and Feichter, J.: Global indirect aerosol effects: a review, Atmos. Chem. Phys., 5, 715-737, doi:10.5194/acp-5-7152005, 2005.

IPCC: Climate Change 2007: The Physical Science Basis. Contribution of Working Group I to the Fourth Assessment Report of the Intergovernmental Panel on Climate Change, Cambridge University Press, Cambridge, United Kingdom and New York, NY, USA, 2007

Moore, R. H., Nenes, A., and Medina, J.: Scanning mobility CCN analysis - A method for fast measurements of size-resolved CCN distributions and activation kinetics, Aerosol Sci. Tech., 44, 861- 
$871,2010$.

Murphy, D. M., Thomson, D. S., and Mahoney, M. J.: In situ measurements of organics, meteoritic material, mercury, and other elements in aerosols at 5 to 19 kilometers, Science, 282, 16641669, 1998.

Nenes, A., Charlson, R. J., Facchini, M. C., Kulmala, M., Laaksonen, A., and Seinfeld, J. H.: Can chemical effects on cloud droplet number rival the first indirect effect?, Geophys. Res. Lett., 29, 1848, doi:10.1029/2002GL015295, 2002.

Osborn, R. J., Taylor, N. F., Spencer, C. W., and Collins, D. R.: Isolation of ambient particles of known critical supersaturation: The Differential Activation Separator (DAS), Aerosol Sci. Tech., 42, 759-772, 2008.

Petters, M. D. and Kreidenweis, S. M.: A single parameter representation of hygroscopic growth and cloud condensation nucleus activity, Atmos. Chem. Phys., 7, 1961-1971, doi:10.5194/acp-71961-2007, 2007.

Petters, M. D., Carrico, C. M., Kreidenweis, S. M., Prenni, A. J., DeMott, P. J., Collett, J. L., and Moosmuller, H.: Cloud condensation nucleation activity of biomass burning aerosol, J. Geophys. Res.-Atmos., 114, D22205, doi:10.1029/2009JD012353, 2009a.

Petters, M. D., Kreidenweis, S. M., Prenni, A. J., Sullivan, R. C., Carrico, C. M., Koehler, K. A., and Ziemann, P. J.: Role of molecular size in cloud droplet activation, Geophys. Res. Lett., 36, L22801, doi:10.1029/2009GL040131, 2009 b.

Raoult, F. M.: Loi générale des tensions de vapeur des dissolvants. Comptes Rendus Hebdomadaires des Seances de l'Academie des Science, 104, 1430-1433, 1887, (in french).

Roberts, G. and Nenes, A.: Continuous-flow streamwise thermalgradient $\mathrm{CCN}$ chamber for atmospheric measurements, Aerosol Sci. Techn., 39, 206-221, 2005.

Rose, D., Gunthe, S. S., Mikhailov, E., Frank, G. P., Dusek, U., Andreae, M. O., and Pöschl, U.: Calibration and measurement uncertainties of a continuous-flow cloud condensation nuclei counter (DMT-CCNC): $\mathrm{CCN}$ activation of ammonium sulfate and sodium chloride aerosol particles in theory and experiment, Atmos. Chem. Phys., 8, 1153-1179, doi:10.5194/acp-8-11532008, 2008.
Rose, D., Nowak, A., Achtert, P., Wiedensohler, A., Hu, M., Shao, M., Zhang, Y., Andreae, M. O., and Pöschl, U.: Cloud condensation nuclei in polluted air and biomass burning smoke near the mega-city Guangzhou, China -Part 1: Size-resolved measurements and implications for the modeling of aerosol particle hygroscopicity and CCN activity, Atmos. Chem. Phys., 10, 33653383, doi:10.5194/acp-10-3365-2010, 2010.

Shantz, N. C., Leaitch, W. R., Phinney, L., Mozurkewich, M., and Toom-Sauntry, D.: The effect of organic compounds on the growth rate of cloud droplets in marine and forest settings, Atmos. Chem. Phys., 8, 5869-5887, doi:10.5194/acp-8-5869-2008, 2008.

Shantz, N. C., Chang, R. Y.-W., Slowik, J. G., Vlasenko, A., Abbatt, J. P. D., and Leaitch, W. R.: Slower CCN growth kinetics of anthropogenic aerosol compared to biogenic aerosol observed at a rural site, Atmos. Chem. Phys., 10, 299-312, doi:10.5194/acp10-299-2010, 2010.

Shilling, J. E., King, S. M., Mochida, M., Worsnop, D. R., and Martin, S. T.: Mass spectral evidence that small changes in composition caused by oxidative aging processes alter aerosol CCN properties, J. Phys. Chem. A, 111, 3358-3368, 2007.

Slowik, J. G., Cziczo, D. J., and Abbatt, J. P. D.: Analysis of cloud condensation nuclei composition and growth kinetics using a pumped counterflow virtual impactor and aerosol mass spectrometer, Atmos. Meas. Tech., 4, 1677-1688, doi:10.5194/amt4-1677-2011, 2011.

Squires, P.: The microstructure and colloidal stability of warm clouds. I. The relation between structure and stability, Tellus, 10, 256-271, 1958.

Stevens, B. and Feingold, G.: Untangling aerosol effects on clouds and precipitation in a buffered system, Nature, 461, 607-613, 2009.

Thomson, S. W.: On the equilibrium of vapour at a curved surface of liquid, Philos. Mag., 4, 448-452, 1871.

Twomey, S.: Pollution and the planetary albedo, Atmos. Environ., 8, 1251-1256, 1974. 